\title{
Article \\ Effects of tDCS on Sound Duration in Patients with Apraxia of Speech in Primary Progressive Aphasia
}

\author{
Charalambos Themistocleous ${ }^{1}{ }^{\mathbb{D}}$, Kimberly Webster ${ }^{2}$ and Kyrana Tsapkini ${ }^{1, *}$ \\ 1 Department of Neurology, Johns Hopkins School of Medicine, Baltimore, MD 21210, USA; cthemis1@jhu.com \\ 2 Department of Otolaryngology, Johns Hopkins Medicine, Baltimore, MD 21210, USA; kwebste1@jhmi.edu \\ * Correspondence: tsapkini@jhmi.edu; Tel.: +1-410-7362940
}

Citation: Themistocleous, $\mathrm{C}$;

Webster, K.; Tsapkini, K. Effects of tDCS on Sound Duration in Patients with Apraxia of Speech in Primary Progressive Aphasia. Brain Sci. 2021, 11, 335. https://doi.org/10.3390/ brainsci11030335

Academic Editor: Paola Marangolo

Received: 31 December 2020

Accepted: 3 March 2021

Published: 6 March 2021

Publisher's Note: MDPI stays neutral with regard to jurisdictional claims in published maps and institutional affiliations.

Copyright: (c) 2021 by the authors. Licensee MDPI, Basel, Switzerland. This article is an open access article distributed under the terms and conditions of the Creative Commons Attribution (CC BY) license (https:// creativecommons.org/licenses/by/ $4.0 /)$.

\begin{abstract}
Transcranial direct current stimulation (tDCS) over the left inferior frontal gyrus (IFG) was found to improve oral and written naming in post-stroke and primary progressive aphasia (PPA), speech fluency in stuttering, a developmental speech-motor disorder, and apraxia of speech (AOS) symptoms in post-stroke aphasia. This paper addressed the question of whether tDCS over the left IFG coupled with speech therapy may improve sound duration in patients with apraxia of speech (AOS) symptoms in non-fluent PPA (nfvPPA/AOS) more than sham. Eight patients with non-fluent PPA/AOS received either active or sham $\mathrm{tDCS}$, along with speech therapy for 15 sessions. Speech therapy involved repeating words of increasing syllable-length. Evaluations took place before, immediately after, and two months post-intervention. Words were segmented into vowels and consonants and the duration of each vowel and consonant was measured. Segmental duration was significantly shorter after tDCS compared to sham and tDCS gains generalized to untrained words. The effects of tDCS sustained over two months post-treatment in trained and untrained sounds. Taken together, these results demonstrate that tDCS over the left IFG may facilitate speech production by reducing segmental duration. The results provide preliminary evidence that tDCS may maximize efficacy of speech therapy in patients with nfvPPA/AOS.
\end{abstract}

Keywords: apraxia of speech (AOS); transcranial direct current stimulation (tDCS); primary progressive aphasia (PPA); inferior frontal gyrus (IFG); sound duration; brain stimulation

\section{Introduction}

Apraxia of speech (AOS) is a condition that affects oral motor speech planning and production. It results in impaired speech fluency due to inhibition of the neural programming of articulation [1]. It can occur in the absence of dysarthria (i.e., a language impairment characterized by paralysis or paresis and muscular control problems) [2] and aphasia (a multimodal language impairment affecting language comprehension and production) $[3,4]$. Usually, AOS results from stroke, but neurodegeneration, traumatic brain injury, genetic disorders, or syndromes (e.g., childhood apraxia of speech) may also trigger AOS [1,5-9]. In this study, we will refer to AOS in the context of primary progressive aphasia (PPA), a neurodegenerative condition with speech and language deficits as its primary symptoms [10-12]. According to the consensus criteria for subtyping of PPA [13], AOS and agrammatism are key symptoms for identifying patients with the non-fluent PPA (nfvPPA) variant from patients with other PPA variants. However, since agrammatism occurs without AOS in some patients [14] and AOS is the only symptom in others [15], a number of studies suggested a clinicopathological presentation of AOS as a distinct PPA variant, primary progressive apraxia of speech (PPAOS) [16-18].

The primary characteristics of AOS are articulatory and prosodic deficits with different degrees of severity (mild to severe) [19,20], resulting in effortful, slow speech, manifested by longer consonants and vowels [21-24]. For example, Duffy and colleagues (2017) [21] argued that slow speech rate and abnormal lexical stress are primary characteristics of 
progressive AOS that make speech in patients with progressive AOS effortful, slow, labored. Thus, longer segmental duration (vowels and consonants) $[25,26]$ constitute a primary deficit of patients with AOS that distinguishes them from patients with other PPA symptoms [21-24]. These measures may also serve as an objective and ecologically valid measure of AOS and an excellent outcome measure to estimate the effects of treatment(s) and symptom progression. Patients with AOS exhibit inconsistent and non-systematic speech articulatory errors and irregular insertions, distortions, deletions, substitutions, and transpositions of sounds [27-30]. They often produce consonants with irregular voicing [31], stop consonants (e.g., /p/ and /t/) with irregular plosive distortions and increased voice onset time (VOT) $[24,26,32]$ or fricative consonants (e.g., /f/ and / $\theta /$ ) with misplacing and/or misshaping the active articulator (tongue) relative to the passive articulator (a place along the palate) [33]. AOS results in reduced coarticulation of adjacent sounds, a slowing down of syllable transitions, and non-canonical syllable segmentation [26]. Further, irregular prosody and rhythm have been reported as characteristics of speech in patients with AOS [34], affecting lexical (e.g., stress) and post-lexical prominence patterns and tonalities.

AOS symptoms have been associated with the left inferior frontal gyrus (IFG), an area involved in kinematic and sound representations of speech production $[6,16,17,35,36]$. Patients with AOS show subtle structural and functional irregularities in the IFG, including other areas of the frontal operculum: the posterior frontal gyrus (i.e., pars opercularis [BA44]), which enables the cognitive selection of vocal and orofacial actions [35,37], the pre-supplementary motor area (pre-SMA), which controls vocalization [17], and the insula under the left IFG, which facilitates articulatory planning [20,38]. BA 44 (pars opercularis) is proximal to the premotor cortex, an area involved in articulation and is bi-directionally connected with BA 40 via the ventral component of the superior longitudinal fasciculus (SLF III). This interaction with BA 40 provides BA 44 (which organizes speech production by selecting the phonemes, the words, and their order to form the sentence to be spoken) with critical phonological information. Thus, this cortico-cortical circuit appears to be the phonological loop in the left hemisphere. This parieto-frontal circuit formed by the SLF III (and perhaps the arcuate fasciculus) is involved in phonological processing [39]. The anterior insula is found to be involved in motor speech planning [40]. Other proximal and distal brain regions have also been associated with AOS, such as the parietal lobe [4], the basal ganglia, and the cerebellum [41]. Additionally, there are few behavioral studies with encouraging results targeting AOS symptoms in nfvPPA/AOS [42].

Transcranial direct current stimulation (tDCS) is a non-invasive brain stimulation that modulates neuronal excitability by modifying neural cells' resting membrane potential either by hyperpolarizing or depolarizing. The placement of the anode (positive electrode) and cathode (negative electrode), intensity, and the duration of stimulation are known to affect the efficacy of tDCS. Recent studies by our group [43] and others [44,45] provided novel insights into the mechanisms of tDCS, showing that changes in functional connectivity (FC) and gamma aminobutyric acid (GABA) concentrations and may be important tDCS mechanisms. We found that tDCS modulated (decreased) functional connectivity (FC) between the stimulated area and the functionally, or structurally, connected temporal areas of the language network, as well as the homologous area in the right hemisphere (but not the default mode network (DMN)); these FC changes were maintained up to 2 months. These results, which are in line with similar decreases in connectivity observed after tDCS over the left IFG in aging [46] and other neurodegenerative conditions, may be interpreted as an indication that fewer resources are needed after tDCS than before for related language tasks. We also tested the hypothesis that $\mathrm{tDCS}$ reduces GABA in the stimulated tissue in PPA. We applied GABA-edited magnetic resonance spectroscopy (MRS) to quantify GABA levels before and after a sham-controlled tDCS intervention with language therapy in PPA. Participants receiving tDCS had significantly greater language improvements than those receiving sham immediately after the intervention and at 2 months follow-up. GABA levels in the targeted tissue decreased after the intervention and remained so for 2 months [43]. 
The association of motor planning and speech articulatory deficits to the left IFG has motivated neuromodulatory studies with tDCS that targeted this area. Specifically, in Marangolo, Marinelli, Bonifazi, Fiori, Ceravolo, Provinciali and Tomaiuolo [19], three subjects with post-stroke aphasia with AOS participated in a randomized double-blinded experiment involving articulatory training in tDCS and sham conditions. Each subject participated in five consecutive daily sessions of anodal tDCS (20 min, $1 \mathrm{~mA}$ ) and sham stimulation over left IFG. tDCS resulted in more improvement than sham condition. Chesters, et al. [47] tested the effect of tDCS in adults who stuttered and found that anodal $\mathrm{tDCS}$ did not improve sentence reading, although, they observed a trend towards a reduction in stuttering when tDCS was coupled with a fluency intervention. In a follow up study, Chesters, et al. [48] tested 30 individuals who stuttered, in which 15 had tDCS and 15 had sham and speech fluency intervention using choral and metronome-timed speech. The authors showed a significant fluency improvement in individuals with tDCS measured one week after the intervention compared to intervention without tDCS. The effects of tDCS were maintained six weeks after therapy during reading but not during conversation. Chester and colleagues concluded that tDCS may be effective for improving speech articulation in other patient populations. Furthermore, the positive effects of tDCS in speech production are supported by studies showing that tDCS improves speech production in typical speakers [49].

Although previous tDCS studies in PPA, including our group's largest-to our knowledge-double-blind, sham-controlled, cross-over trial of tDCS efficacy in PPA have shown positive effects of tDCS on spoken and written naming and spelling [50-55], there is no tDCS study demonstrating the potential of tDCS in reducing AOS symptoms despite the fact that AOS is a prominent feature in patients with nfvPPA or PPAOS (here referred to as nfvPPA/AOS to avoid classification debates). To our knowledge, this is the first study to provide preliminary, proof-of-concept evidence of tDCS efficacy as an adjuvant to speech therapy in PPA patients with AOS symptoms. The present study does not intend to suggest any criterion about AOS diagnosis or test the reliability of perceptual judgments for PPAOS diagnosis (e.g., Dabul et al.'s, questionnaire), or provide evidence for the presence or absence of AOS derived from perceptual judgments. The present study tests a simple hypothesis: if temporal acoustic measures, such as longer sound durations, are a characteristic of AOS [19-27], and the left IFG is a critical area for motor planning in speech production $[6,16,17,36-40]$, then $\mathrm{tDCS}$ over the left IFG may normalize these sound durations significantly better than speech therapy alone in nfvPPA/AOS.

In the present study, we hypothesized that tDCS over the left IFG coupled with speech production therapy will reduce AOS symptoms in patients with nfvPPA/AOS more than sham, i.e., speech production treatment alone. We used sound duration as a measure of AOS symptoms and reduced sound duration as an improvement of speech production in these patients. As slow speech production is a distinguishing characteristic of speech for patients with nfvPPA/AOS, a decrease in sound duration was considered as a therapeutic improvement corresponding to faster speech articulation. We asked three questions: (1) is tDCS more effective than sham in reducing sound duration in patients with nfvPPA/AOS? (2) Are tDCS effects sustainable over a two-months period? (3) Do tDCS effects generalize to untrained items? To answer these questions, we designed an experimental study where patients with nfvPPA/AOS received anodal tDCS over the left IFG or sham stimulation for the same duration paired with a word repetition task. Patients were evaluated three times: before treatment, immediately after treatment, and two months post-treatment. All words produced were segmented into vowels and consonants and we measured their temporal properties. Changes in syllable length do not affect equally their constituents, namely the vowels and consonants that make up these syllables [26,56,57], as changes in length primarily involve vowels. Therefore, the effects of tDCS on vowel and consonant duration may be different, which motivated us to study the two sound categories separately. 


\section{Materials and Methods}

\subsection{Study Design and Participants}

The study had a double-blind, cross-over design with two periods. In the present study, we analyzed only the first period to avoid potential carryover effects. Eight patients with nfvPPA/AOS participated and were recruited from Johns Hopkins clinics or referrals from diagnostic centers. Inclusion criteria were as follows: native English speakers, minimum of high-school education, progressive speech/language disorder diagnosis, and absence of developmental or other neurogenic disorders (e.g., stroke). All participants provided informed consent. We included only those patients with nfvPPA and AOS symptoms (i.e., nfvPPA/AOS). Patients received tDCS or sham for three weeks (15 sessions) and were evaluated three times: before therapy, immediately after therapy, and two months posttherapy. Five participants received anodal tDCS over the left IFG and three participants received sham stimulation, both paired with speech therapy. Patients in the tDCS and sham groups were matched for baseline demographic characteristics and language severity. They were also matched for the segmental duration, which was the dependent variable of the study.

\subsection{Clinical Assessment}

The subtyping of individuals with nfvPPA/AOS followed formal consensus criteria of PPA and was based on cognitive, speech and language testing, neurological examination, and neuroimaging [13]. Table 1 shows the demographic (e.g., age at the beginning of therapy, sex, education) and neuropsychological evaluations for each participant. We report on patients' performance on the digit span forward and backward, a test measuring short-term and working memory, the Pyramids and Palm Trees [58], a test measuring semantic knowledge, the Boston Naming Test (BNT) [59], a test measuring confrontational naming, and the Subject-relative, Object-relative, Active, and Passive (SOAP), a test for syntactic comprehension [60], and letter and semantic fluency [61]. We also report on disease progression using Fronto-temporal Dementia Clinical Dementia Rating (FTD-CDR) Scale scores for language and total severity (sum of domains) [62]. Severity scores for each domain range from normal (0) to questionable/very mild (0.5), mild (1.0), moderate (2.0), and severe (3.0). Domains included are memory, orientation, judgment and problemsolving, community affairs, home and hobbies, personal care, behavior/comportment, personality, and language [62].

\subsection{Speech Therapy Methods}

Speech therapy was conducted for 45 min total, with tDCS or sham stimulation occurring concurrently for the first $20 \mathrm{~min}$. The therapy task involved oral word repetition of increasingly complex words (e.g., method, methodology, methodological) modeled after Dabul et al.'s standardized assessment [63]. We used ten triplets of increasing morphological complexity for trained words and ten triplets for untrained words matched for frequency, complexity, and length. The trained words were practiced during each therapy session whereas the untrained words were never practiced but were evaluated at all timepoints for both tDCS and sham groups. Patients were initially trained on shorter words and when criterion was met ( $80 \%$ phonetic correctness) they proceeded to the list with increased syllables. The goal was to improve volitional control of participants' articulators in order to produce co-articulated, intelligible speech, as well as to improve precision of articulation, speech rate, and speech fluency. 
Table 1. Demographic and neuropsychological data of the participants (numbers out of parenthesis in column mean, indicate the mean and in parenthesis the standard deviation). Total Severity = total severity scale from the Fronto-temporal Dementia Clinical Dementia Rating Scale [62]; Language Severity is the part of the Total Severity FTD-CDR that scores language skills; FAS = The F-A-S Test, a subtest of the Neurosensory Center Comprehensive Examination for Aphasia (NCCEA) [61]; BNT (30) = Boston Naming Test [59]; SOAP Total = Subject-relative, Object-relative, Active, and Passive total score [60]; $p$ values are reported from a Kruskal-Wallis rank sum test; ${ }^{*}=$ significant.

\begin{tabular}{|c|c|c|c|c|c|c|c|c|c|c|c|}
\hline \multirow[b]{2}{*}{ Participant } & \multicolumn{4}{|c|}{ Sham } & \multicolumn{6}{|c|}{ tDCS } & \multirow[b]{2}{*}{$p$} \\
\hline & $\mathrm{ABN}$ & DAN & JJI & Mean & BIN & DRY & GSH & JBN & CDY & Mean & \\
\hline Education & 16 & 16 & 16 & $16(0)$ & 16 & 16 & 20 & 20 & 16 & $18(2.30)$ & 0.2 \\
\hline Gender & $\mathrm{F}$ & $\mathrm{F}$ & $\mathrm{M}$ & - & M & $\mathrm{F}$ & M & M & $\mathrm{F}$ & - & \\
\hline $\begin{array}{l}\text { Condition onset } \\
\text { (years) }\end{array}$ & 4 & 2.5 & 1.5 & $2.7(1.3)$ & 3 & 3.5 & 6 & 2 & 4 & $3.7(1.48)$ & 0.2 \\
\hline Age at start of Therapy & 54 & 71 & 78 & $67.67(5.27)$ & 65 & 53 & 68 & 65 & 74 & $65(7.64)$ & 0.5 \\
\hline $\begin{array}{c}\text { FTD-CDR Language } \\
\text { Severity }\end{array}$ & 2 & 1 & 2 & $1.67(0.58)$ & 1 & 0.5 & 2 & 0.5 & 1 & $1(0.6)$ & 0.2 \\
\hline $\begin{array}{c}\text { FTD-CDR Total } \\
\text { Severity }\end{array}$ & 4 & 4.5 & 5.5 & $4.67(0.54)$ & 2 & 0.5 & 2.5 & 1 & 1.5 & $1.5(0.79)$ & 0.03 * \\
\hline F.A.S. & 6 & 11 & 4 & $7(3.51)$ & 21 & 34 & 21 & 31 & 15 & $24.4(7.86)$ & 0.02 * \\
\hline $\begin{array}{l}\text { Fruits, Animals, } \\
\text { Vegetables }\end{array}$ & 38 & 11 & 10 & $19.67(5.32)$ & 33 & 54 & 33 & 42 & 28 & $38(10.27)$ & 0.2 \\
\hline Digit Span Forward & 3.5 & 4 & 3.5 & $3.67(0.25)$ & 4.5 & 5.5 & 3.5 & 6 & 7 & $5.3(1.35)$ & 0.09 \\
\hline Digit Span Backward & 2 & 3.5 & 2.5 & $2.67(0.54)$ & 4.5 & 5 & 3.5 & 3 & 5.5 & $4.3(1.04)$ & 0.07 \\
\hline $\begin{array}{l}\text { Pyramids and } \\
\text { Palm Trees }\end{array}$ & 15 & 15 & 15 & $15(0)$ & 15 & 15 & 15 & 15 & 15 & $15(0)$ & 1 \\
\hline BNT (30) & 28 & 28 & 15 & $23.67(6.62)$ & 29 & 30 & 24 & 30 & 23 & $27(3.4)$ & 0.3 \\
\hline SOAP Total (40) & 30 & 33 & 27 & $30(4.24)$ & 35 & 37 & 35 & 33 & 37 & $35(1.7)$ & 0.03 * \\
\hline
\end{tabular}

\section{4. $t D C S$ Methods}

To estimate current distribution and guide experimental design, we conducted a current flow analysis for some of our patients of the main trial (see Figure 1), for whom we could obtain those specific scans $[64,65]$. Stimulation was delivered using the Soterix Transcranial Direct Current Stimulator Clinical Trials Model 1500 at $2 \mathrm{~mA}$ intensity for 20 min for a total of $40 \mathrm{~mA}$ per session (estimated current density $0.08 \mathrm{~mA} / \mathrm{cm}^{2}$ ) [66]. Current was transferred via nonmetallic, conductive rubber electrodes covering $5 \times 5 \mathrm{~cm}(2.54 \mathrm{~cm} / \mathrm{inch})$ saline-soaked sponges. The anode was placed over the entire left IFG (see Figure 1) which corresponds to the F7 electrode $[53,67,68]$ based on the electroencephalogram (EEG) 1020 electrode position system [69]. The left IFG was co-registered to pretreatment magnetic resonance imaging (MRI) scans using a fiducial marker. The cathode was placed on the right cheek. Extracephalic cathodal placement has been shown to better target the area in question (Russell, 2006). Both the participant and the speech-language pathologist were blind to the stimulation condition by means of pre-registered codes on the tDCS device [66]. To mask the condition from participants, sham stimulation involved a short period of electrical current at stimulation onset, ramping up for $30 \mathrm{~s}$ and then ramping down, triggering a tingling sensation, which has been shown to blind the participant by creating the same initial sensation as in the tDCS condition [70]. To better simulate the actual tDCS condition during sham condition, we had our device modified to induce a second ramp up and down of the current for $30 \mathrm{~s}$ in the middle of the stimulation (about 10 min post-onset) creating an additional short-term tingling sensation to facilitate masking during sham. Patients were debriefed after treatment on whether they received sham or real tDCS and their responses were at chance (53\% correct). Participants were asked to report their overall pain level using the Wong-Baker FACES Pain Rating Scale (www.WongBakerFACES.org, accessed on 10 June 2020). 


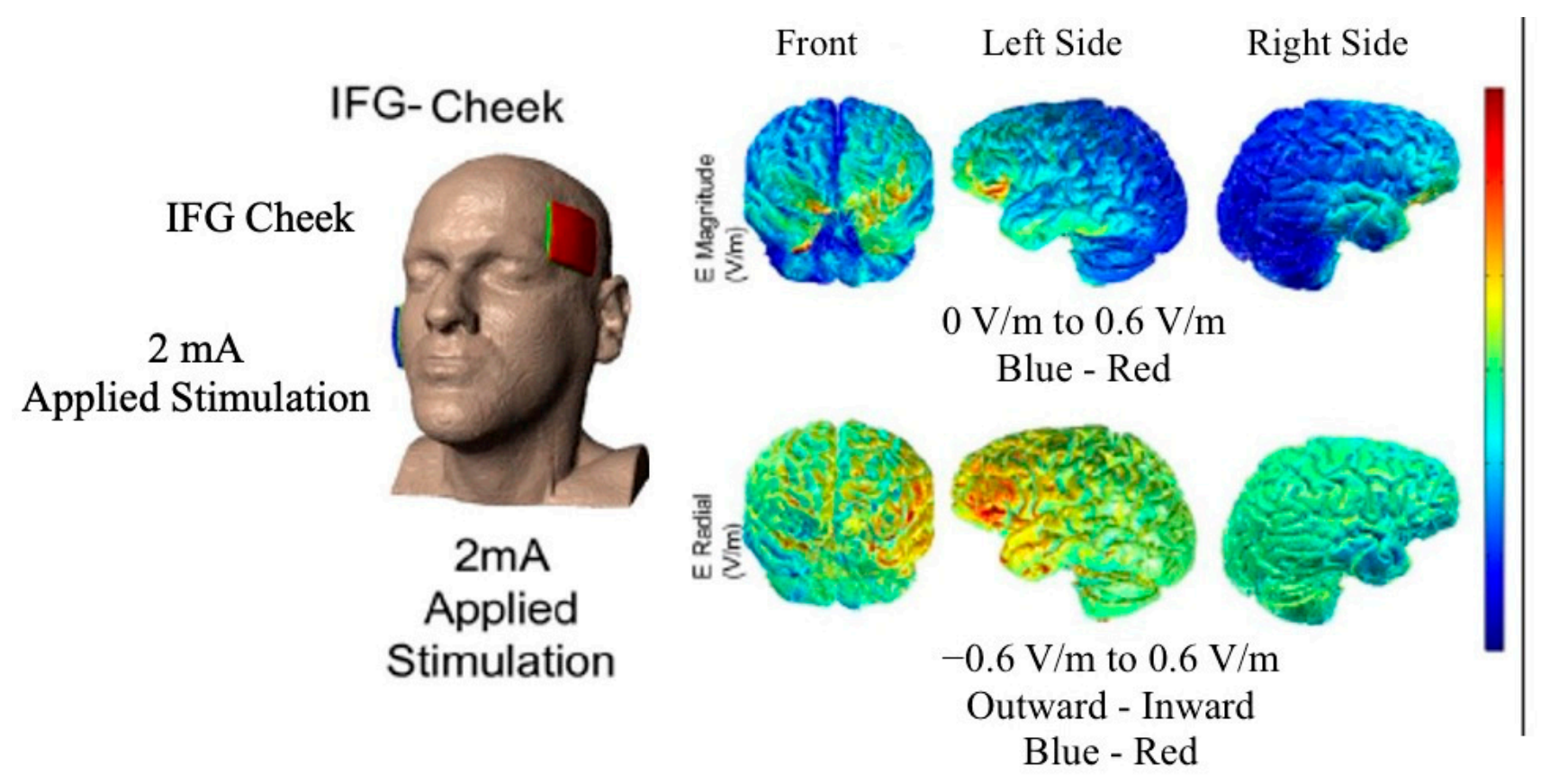

Figure 1. Model of current distribution for used stimulation montage (image courtesy of Dr. Marom Bikson).

\subsection{Acoustic Analysis}

All evaluations (before, immediately after, and 2 months post-therapy) were recorded using an audio recorder that was placed approximately $1 \mathrm{ft}$ in front of the patient. Audio recordings were converted into a $16,000 \mathrm{~Hz}$ mono wav file. All word productions were manually split to distinguish the clinician and patient. Figure 2 shows the waveform in the upper tier for the word "methodology", which served as part of the triplet method, methodology, methodological (see Appendix A for the whole set of words evaluated); the spectrogram is shown under the waveform. The thin vertical lines that extend from the spectrogram to the penultimate tier (measured from top to bottom) indicate the boundaries of vowels and consonants. Each individual sound is denoted in the penultimate tier using the international phonetic alphabet. The whole word is shown in the last tier.

We segmented all individual vowels and consonants uttered by clinicians and patients that made up each keyword as shown in Figure 2 (see also Appendix B, for word characteristics). The segmentation and labeling of vowels and consonants was conducted manually by simultaneous inspection of waveforms and wide-band spectrograms and following standard criteria of segmentation [71]. The onset and offset of the first two vowel formants (F1 and F2) and the fundamental frequency (F0) were employed for the identification of vowels [72,73]. The onset and offset of frication (i.e., the noisy portion) was employed for the identification of fricatives [74,75]. Stop consonants were measured at the onset of the closure phase, including the burst [76]. Segmentation was primarily conducted by the first author and a research assistant. To check for reliability of the segmentation procedures, the first author re-measured 3.5\% of the data measured by the research assistant. The duplicate durational measurements of sounds were evaluated using Cohen's cappa ( $\kappa=0.97$, $p<0.0001)$ and show significant agreement. All acoustic analyses were conducted in Praat [71], an acoustic analysis software [77]. From the segmented keywords, we measured the duration of each individual consonant and vowel. To compare consonant and vowel duration between patients and healthy controls, we acoustically analyzed clinicians' productions, which were provided as prompts in the repetition task during evaluations. 


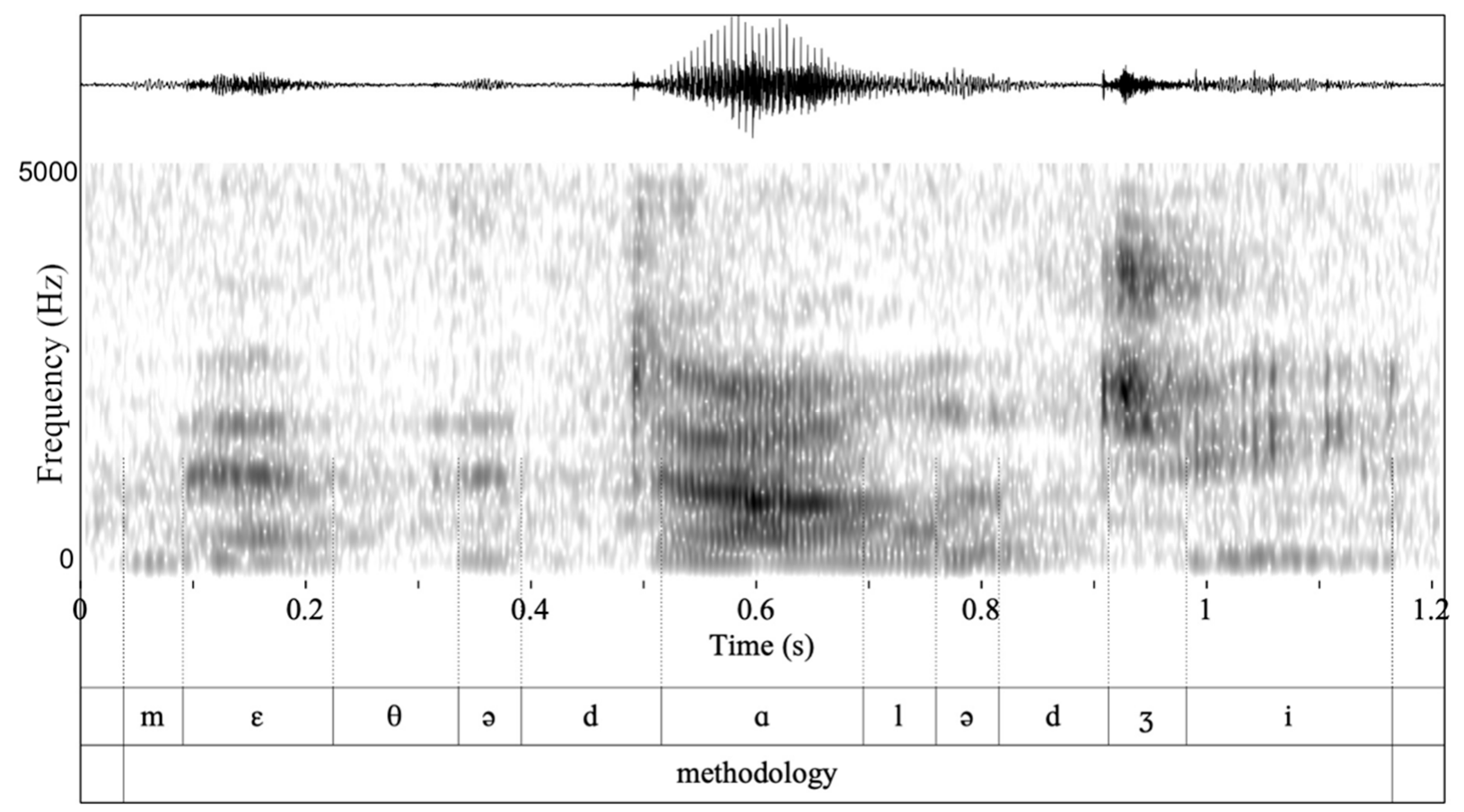

Figure 2. Waveform and spectrogram of the word methodology/,me日ə'dalədzi/ uttered by a female patient with nfvPPA/AOS. The middle tier shows with thick vertical lines the boundaries of vowels and consonants and the lower shows the target word.

\subsection{Statistical Analysis}

Patients that received $\mathrm{tDCS}$ and sham were matched for segmental duration, the dependent variables of the study, thus they were not different at baseline. To remediate potential confounds due to unequal group sizes, we additionally used a linear mixed effect model that addresses unbalanced designs. We included the participant as a random slope to control for the individual differences between patients, even though the differences in FTD-CDR Total Severity, F.A.S., and SOAP do not reflect on the sound duration at baseline (see Figure 3). Unlike the regression analysis and the analysis of variance (ANOVA), these models incorporate fixed and random effects [78]. The fixed effects are the parameters that we controlled experimentally (stimulation condition and timepoint). The random slope controls for individual differences in the error and increases the robustness of the fixed factors [78,79]. We conducted six linear mixed effects models in $\mathrm{R}$ (three for trained and three for untrained items) with the duration of vowels, consonants, and the total sound duration, which pools the duration of vowels and consonants, as dependent variables, and the condition (tDCS vs. sham) and timepoint (before, after, and two months post-therapy) as predictors. To model individual differences of participants, the participant was modelled as a random slope. The linear mixed effects models for trained and untrained items are shown in (1) to (3):

$$
\begin{gathered}
\text { Sound duration } \sim \text { condition } * \text { timepoint }+(1 \mid \text { participant }) \\
\text { Vowel duration } \sim \text { condition } * \text { timepoint }+(1 \mid \text { participant }) \\
\text { Consonant duration } \sim \text { condition } * \text { timepoint }+(1 \mid \text { participant })
\end{gathered}
$$

Linear mixed effects models were designed in R [80] using the "Ime4: Linear MixedEffects Models using 'Eigen' and S4" package [81], and $p$ values were calculated using the LmerTest package [82]. To compute post hoc contrasts, we employed the R package emmeans (EMMs, also known as least-squares means), which provides estimated marginal means [83]. A t test was performed to compare the duration of vowels and consonants produced by patients and clinicians. 

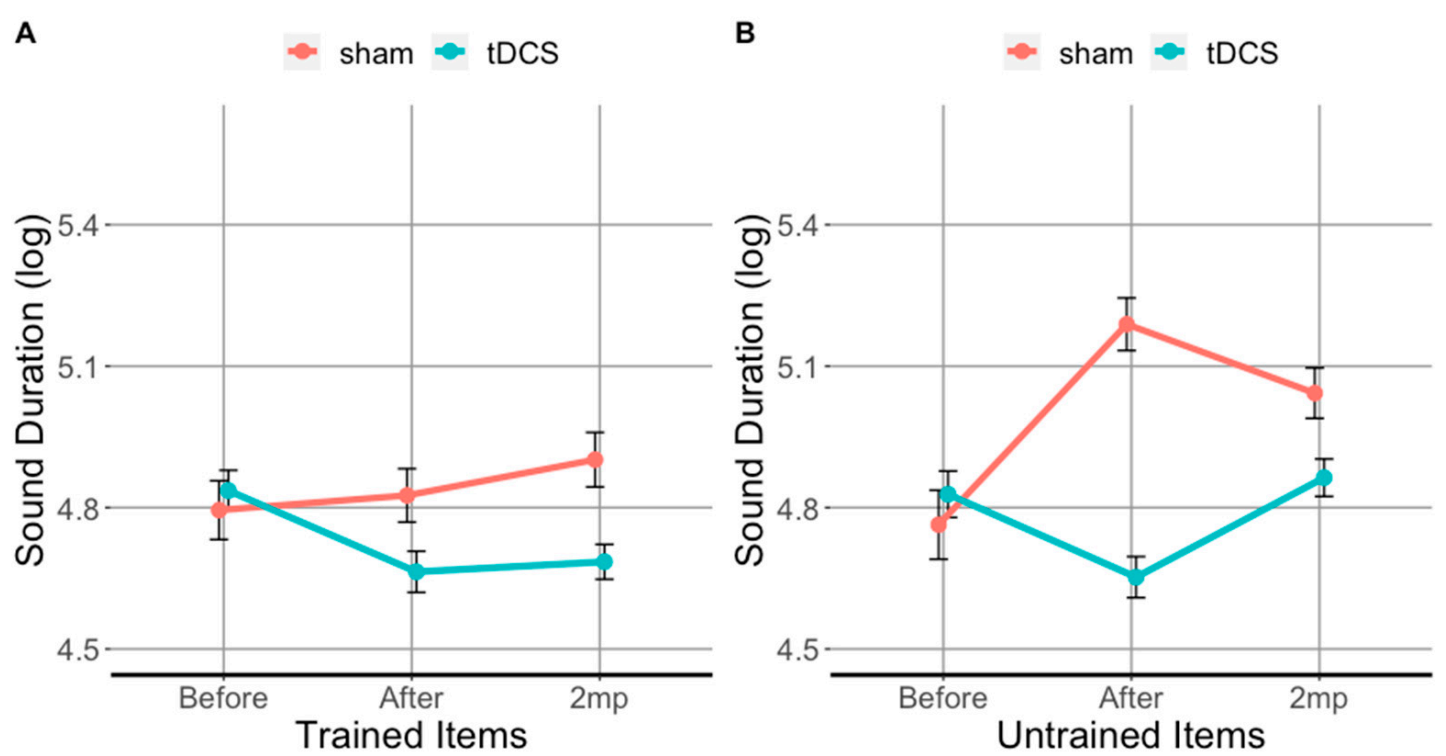

Figure 3. Trained items (A) and untrained items (B) evaluated before (before), immediately after (after), and 2 months post-treatment $(2 \mathrm{mp}$ ) for each stimulation condition. The ordinate shows the segmental (vowels and consonants) duration (log transformed), error bars show 95\% CI; lower values: shorter segments/faster production. Turquoise lines show tDCS effects; red lines show sham effects.

\section{Results}

At baseline (Figure 4A), the sound duration for trained items did not differ between patients who received tDCS and sham $(t(3009)=0.4, p=0.7)$. Both tDCS and sham patient groups produced significantly longer sounds (trained and untrained) than healthy controls (i.e., the clinicians). However, immediately after treatment (Figure 4B), patients who received tDCS produced significantly shorter sounds than those who received sham $(t(2508)=15, p<0.0001)$, and their sound durations approximated those produced by clinicians (see Figure 4B). Importantly, patients who received tDCS maintained the tDCSrelated gains at the 2 months post treatment evaluation for trained items (see Figure 4C). Overall, tDCS resulted in significantly shorter sound durations immediately after and at 2 months post-treatment for both trained and untrained items. We will first present the tDCS vs. sham comparison in trained (i) and untrained items (ii), and then separately for vowels (iii, iv) and consonants (v, vi).

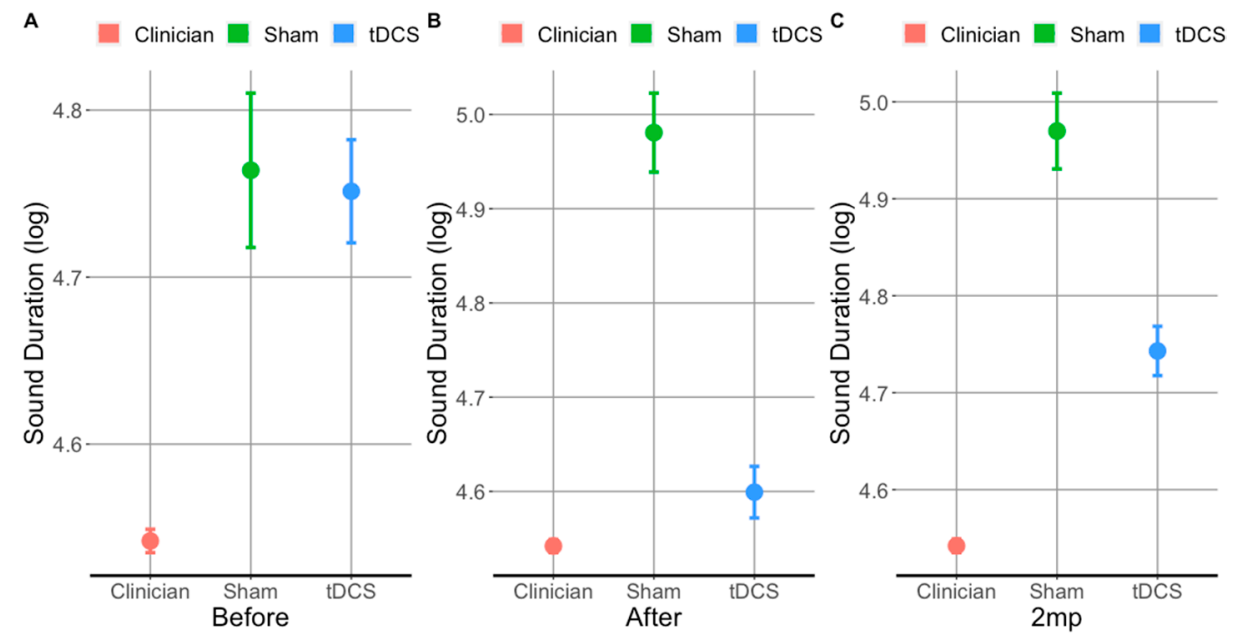

Figure 4. Sound (vowels and consonant) duration (trained and untrained) (log transformed) produced by clinicians and patients that received tDCS and sham evaluated before (A), after (B), and 2 months post-treatment (C). Error bars show 95\% CI; lower values: shorter segments/faster production. 


\section{1. tDCS Effectiveness on Sound Duration in Trained Items}

The results for sound duration in the trained items are shown in Figure $3 \mathrm{~A}$ and Table 2A. Immediately after therapy, sounds in trained items were $26 \%$ shorter in the tDCS condition compared to sham. This reduction in sound duration was significant as shown by the post hoc analysis using EMMs $(\beta=-0.32, S E=0.04, d f=4900.5, t=-64.48$, $p=0.0001$ ). At 2 months post-therapy, sounds in trained words were $29 \%$ shorter in tDCS condition compared to sham and the reduction was significant as well $(\beta=-0.26, S E=0.05$, $d f=4899.01, t=-5.47, p=0.0001)$. Compared to baseline, sounds in trained words were $19 \%$ shorter immediately after therapy $(\beta=0.234, S E=0.035, z(6.800), p<0.0001)$ and $14 \%$ shorter at 2 months post-therapy which is a significant reduction $(\beta=0.234, S E=0.035$, $z(6.800), p<0.0001)$.

Table 2. Linear Mixed effects models on the effects of condition (tDCS vs. sham) and period (Before, Immediately After, 2 months post treatment ( $2 \mathrm{mp}$ )) on trained (top) and untrained sound duration (bottom). The intercept of the model is the value of sham at baseline (Before).

\begin{tabular}{lcccccc}
\hline & & Estimate & $S E$ & $d f$ & $t$ & $p$ \\
\hline A. Trained Items & Intercept & 4.7955 & 0.1657 & 6.1702 & 28.95 & $<0.0001$ \\
& tDCS vs. sham After & -0.3194 & 0.0493 & 4900.5593 & -6.48 & $<0.0001$ \\
& tDCS vs. sham at 2 m post & -0.2559 & 0.0468 & 4899.0188 & -5.47 & $<0.0001$ \\
\hline B. Untrained Items & Intercept & 4.7427 & 0.1838 & 6.12 & 25.81 & 0009 \\
& tDCS vs. sham After & -0.59 & 0.0539 & 4118.06 & -11.02 & $<0.0001$ \\
& tDCS vs. sham at 2 m post & -0.26 & 0.0495 & 4113.87 & -5.19 & $<0.0001$ \\
\hline
\end{tabular}

\section{2. $t D C S$ Effectiveness on Sound Duration in Untrained Items}

Figure $3 \mathrm{~B}$ and Table $2 \mathrm{~B}$ show the results for sound duration in untrained items. Immediately after therapy, sounds in untrained words were $47 \%$ shorter in tDCS condition compared to sham and $22 \%$ shorter 2 months post-therapy. Compared to baseline, sounds in untrained words in the tDCS condition were $14 \%$ shorter immediately after therapy $(\beta=24, S E=5, z(5.100), p<0.0001)$. However, only a $2 \%$ difference in sound duration was observed at 2 months post-therapy for tDCS condition $(\beta=0, S E=5, z(0.000), p=1)$. Compared to baseline, sounds in untrained words in the sham condition were $26 \%$ longer immediately after therapy period $(\beta=-47, S E=6, z(-7.600), p<0.0001)$ and $19 \%$ longer at 2 months post-therapy $(\beta=-29, S E=5, z(-5.600), p<0.0001)$.

\section{3. tDCS Effectiveness on Vowel Duration in Trained Items}

Figure 5A and Table 3A show the results for vowel duration in the trained items. Immediately after therapy, vowels in trained words in the tDCS condition were $27 \%$ shorter compared to sham $(\beta=-0.2434, S E=0.069, d f=2043.05, t=-3.54, p=0.001)$. At 2 months post-therapy, vowels in trained words in the tDCS condition were $33 \%$ shorter compared to sham $(\beta=-0.2820, S E=0.07, d f=2041.63, t=-4.29, p=0.001)$. With respect to baseline, vowels in trained words in the tDCS condition were $19 \%$ shorter immediately after therapy ( $\beta=0.27, S E=0.047, t=5.900, p<0.0001)$ and $15 \%$ shorter 2 months post-therapy $(\beta=0.17$, $S E=0.041, t=4.200, p<0.0001)$. No significant change was observed with respect to baseline in sham condition as vowels in trained words were $5.3 \%$ longer immediately after therapy $(\beta=0.33, S E=0.219, t=1.500, p=0.68)$ and $11 \%$ longer 2 months post-therapy $(\beta=-0.11, S E=0.052, t=-2.100, p=0.27)$.

\section{4. tDCS Effectiveness on Vowel Duration in Untrained Items}

Figure $5 \mathrm{~B}$ and Table 3B show the results for vowel duration in the untrained items. Immediately after therapy, vowels in untrained words in the tDCS condition were $55 \%$ shorter compared sham. They were 30\% shorter at 2 months post-therapy compared to sham. With respect to baseline in the tDCS condition, vowels in untrained words were $18 \%$ shorter immediately after therapy $(\beta=0.24, S E=0.043, \mathrm{t}=5.500, p<0.0001)$ and $5 \%$ shorter at 2 months post-therapy $(\beta=-0.02, S E=0.043, t=-0.4, p=1)$. With respect to 
baseline in the sham condition, vowels in untrained words were $20 \%$ longer immediately after therapy $(\beta=-0.37, S E=0.060, t=-6.100, p<0.0001)$ and $17 \%$ longer at 2 months post-therapy $(\beta=-0.26, S E=0.051, t=-5.100, p<0.0001)$.
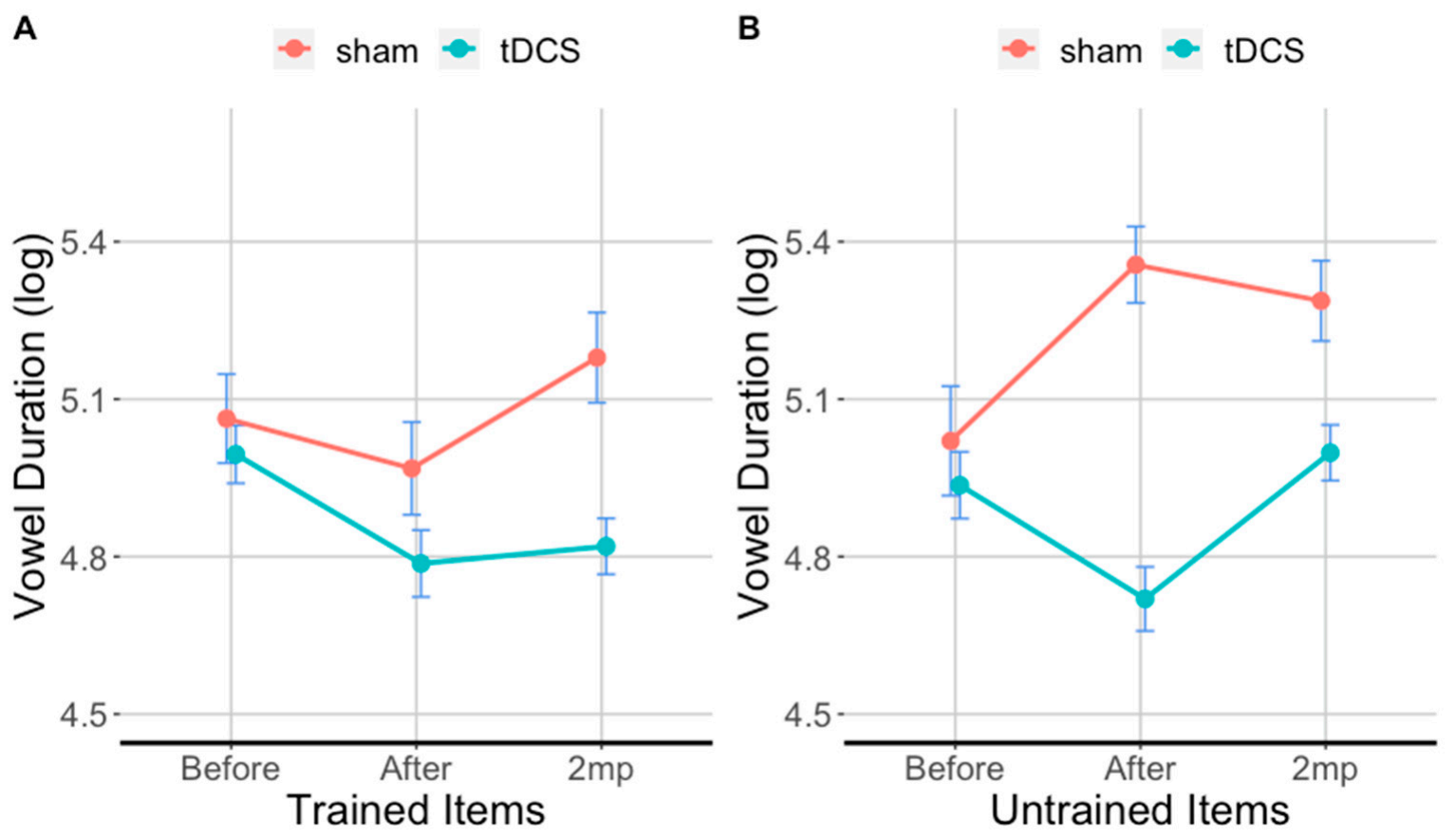

Figure 5. Trained items (A) and untrained items (B) evaluated before (before), immediately after (after), and 2 months post-treatment ( $2 \mathrm{mp}$ ) for each condition. The ordinate shows vowel duration (log transformed), error bars show $95 \% \mathrm{CI}$; lower values: shorter segments/faster production. Turquoise lines show tDCS effects; red lines show sham effects.

Table 3. Linear Mixed effects models on the effects of condition (sham vs. tDCS) and period (Before, After, 2 months post therapy (2 mp)) on trained (top) and untrained vowel duration (bottom). The intercept of the model is the value of sham in the before phase.

\begin{tabular}{|c|c|c|c|c|c|c|}
\hline & & Estimate & $S E$ & $d f$ & $t$ & $p$ \\
\hline \multirow[t]{3}{*}{ A. Trained Items } & Intercept & 5.0919 & 0.1728 & 6.3419 & 29.47 & $<0.0001$ \\
\hline & $\begin{array}{l}\text { tDCS in the After } \\
\text { timepoint }\end{array}$ & -0.2434 & 0.0687 & 2043.0476 & -3.54 & 0004 \\
\hline & tDCS in the $2 \mathrm{mp}$ timepoint & -0.2820 & 0.0657 & 2041.6251 & -4.29 & $<0.0001$ \\
\hline \multirow[t]{3}{*}{ B. Untrained Items } & Intercept & 5.0122 & 0.1740 & 6.3172 & 28.81 & $<0.0001$ \\
\hline & $\begin{array}{l}\text { tDCS in the After } \\
\text { timepoint }\end{array}$ & -0.6013 & 0.0738 & 1802.2565 & -8.15 & $<0.0001$ \\
\hline & tDCS in the $2 \mathrm{mp}$ timepoint & -0.2455 & 0.0670 & 1797.7502 & -3.66 & 0002 \\
\hline
\end{tabular}

\section{5. tDCS Effectiveness on Consonant Duration in Trained Items}

Figure 6A and Table 4A show the results for consonant duration in the trained items. Consonants in the tDCS condition were $20 \%$ shorter than in the sham condition in the after period, and $17 \%$ shorter than sham in the 2 months post speech therapy. With respect to baseline consonants in trained items with tDCS were 15\% shorter in the after period ( $\beta=0.176, S E=0.046, t=3.8, p<0.0001) 10 \%$ shorter in the 2 months post therapy period, an effect that was not significant $(\beta=0.108, S E=0.041, t=2.60 p=0.09)$. With respect to baseline, consonants in sham condition were only $3.6 \%$ longer in the after period $(\beta=-0.16, S E=0.045, t=-3.400, p<0.01)$ and $4.3 \%$ longer in the 2 months post therapy period $(\beta=-0.116, S E=0.045, t=-2.6, p=0.1100$. 

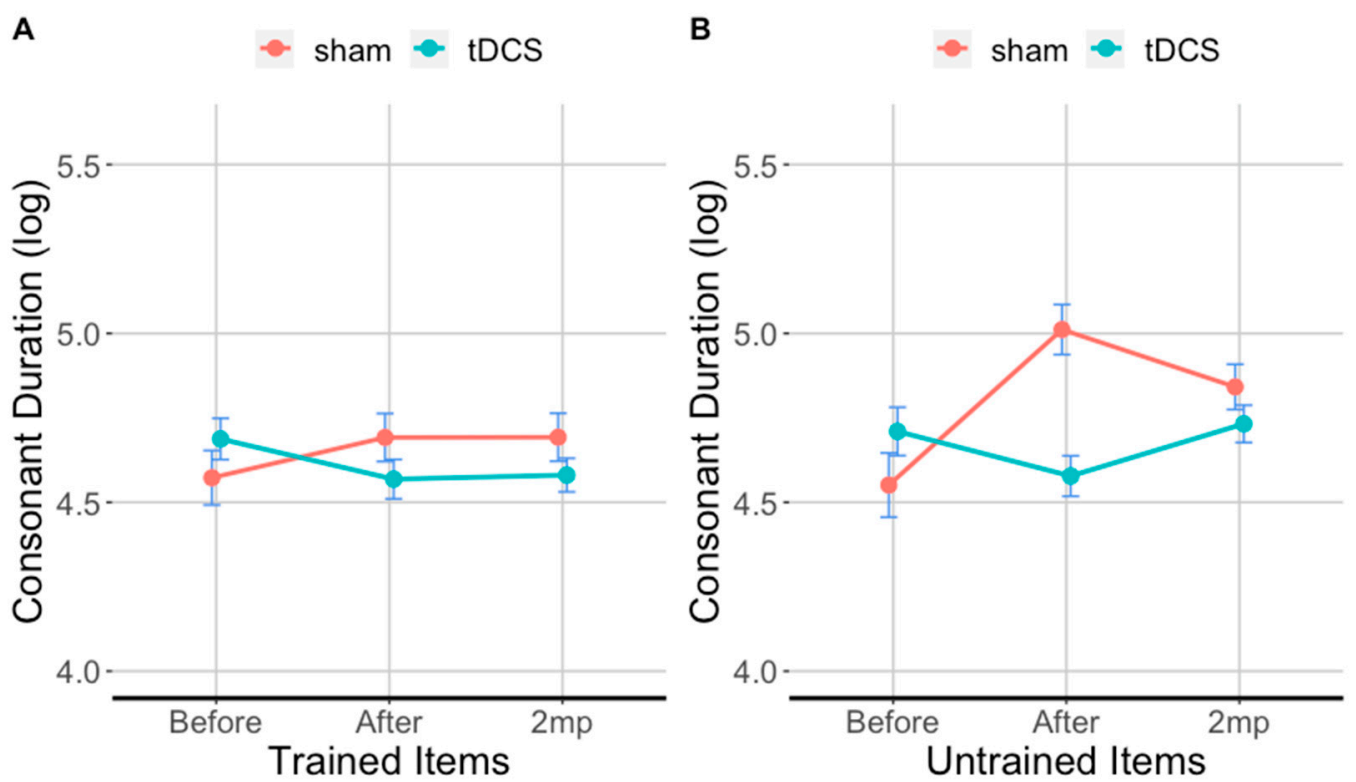

Figure 6. Trained items (A) and untrained items (B) evaluated before (before), immediately after (after), and 2 months post-treatment ( $2 \mathrm{mp}$ ) for each condition. The ordinate shows consonant duration (log transformed), error bars show $95 \%$ CI; lower values: shorter segments/faster production. Turquoise lines show tDCS effects; red lines show sham effects.

Table 4. Linear mixed effects models on the effects of condition (sham vs. tDCS) and period (BeFigure 2. months post therapy $(2 \mathrm{mp})$ ) on trained (top) and untrained consonant duration (bottom). The intercept of the model is the value of sham in the before phase.

\begin{tabular}{|c|c|c|c|c|c|c|}
\hline & & Estimate & $S E$ & $d f$ & $t$ & $p$ \\
\hline \multirow[t]{3}{*}{ A. Trained Items } & Intercept & 4.5697 & 0.1647 & 6.2897 & 27.75 & $<0.0001$ \\
\hline & $\begin{array}{l}\text { tDCS in the After } \\
\text { timepoint }\end{array}$ & -0.3307 & 0.0647 & 2804.4270 & -5.11 & $<0.0001$ \\
\hline & tDCS in the $2 \mathrm{mp}$ timepoint & -0.2239 & 0.0613 & 2803.4093 & -3.65 & 0.00027 \\
\hline \multirow[t]{3}{*}{ B. Untrained Items } & Intercept & 4.5255 & 0.1897 & 6.1737 & 23.85 & $<0.0001$ \\
\hline & $\begin{array}{l}\text { tDCS in the After } \\
\text { timepoint }\end{array}$ & -0.5427 & 0.0726 & 2259.5804 & -7.48 & $<0.0001$ \\
\hline & tDCS in the $2 \mathrm{mp}$ timepoint & -0.2540 & 0.0668 & 2255.8899 & -3.80 & 0.00015 \\
\hline
\end{tabular}

\section{6. tDCS Effectiveness on Consonant Duration in Untrained Items}

Figure $6 \mathrm{~B}$ and Table $4 \mathrm{~B}$ show the results for consonant duration in the untrained items. Immediately after therapy, consonants in untrained items in the tDCS condition were $36 \%$ shorter compared to sham. At 2 months post-therapy, consonants in untrained items in the tDCS condition were $14 \%$ shorter compared to sham. With respect to baseline, consonants in untrained items in the tDCS condition were $10 \%$ shorter immediately after therapy, $(\beta=0.13, S E=0.046, t=2.9, p<0.05)$ and there was a $0 \%$ difference at 2 months posttherapy $(\beta=-0.03, S E=0.05, t=-0.700, p=0.9800)$. For consonants in untrained items in the sham condition, duration was $30 \%$ longer immediately after $(\beta=-0.41, S E=0.06$, $t=-7.2, p=0.0001)$ and $18 \%$ longer 2 months post-therapy $(\beta=-0.27, S E=0.241$, $t=-1.100, p=0.85)$ compared to baseline.

\section{Discussion}

In this study, we investigated whether tDCS over the left IFG coupled with speech therapy improves sound duration in patients with nfvPPA/AOS more than sham, i.e., speech therapy alone. First, we evaluated whether tDCS is more effective than sham in improving sound duration in patients with nfvPPA/AOS and whether effects sustained for 2 months post-treatment. Second, we evaluated whether the effects of tDCS generalized to untrained items. Third, we evaluated whether effects differed between vowels and consonants. Our 
findings show that (1) tDCS in conjunction with speech therapy reduces sound duration significantly more than speech therapy alone (sham). Furthermore, tDCS effects sustained over time, i.e., the tDCS advantage was maintained for up to 2 months post-treatment. (2) The effects of tDCS generalized to untrained items immediately after treatment but this improvement was not maintained at 2 months post-treatment. (3) Patients who received tDCS coupled with speech therapy produced shorter vowels and consonants than patients who received speech therapy alone (sham). Below, we discuss the findings in detail, the contribution and limitations of this study, and future directions.

The most important finding of this study is that tDCS reduced sound duration immediately after and up to 2 months post-treatment with respect to baseline for trained and untrained items. Furthermore, in trained items, sound duration approached the sound duration of healthy controls, although sounds produced by patients with nfvPPA/AOS were still significantly longer than those produced by healthy controls. In sham condition, sound duration slightly increased (1.2\%) immediately after treatment with respect to baseline and remained the same at 2 months post treatment. This study shows that combining speech training with tDCS induces more sustaining effects. Such sustaining effects of tDCS were observed in other studies related to speech fluency and articulation. For example, Marangolo, Marinelli, Bonifazi, Fiori, Ceravolo, Provinciali and Tomaiuolo [19] also found improvement in response accuracy 2 months post-treatment in three patients with stroke-induced speech apraxia. Chesters, Mottonen and Watkins [48] showed that the tDCS effect on stuttering severity sustained for six weeks post-treatment in reading (but not in conversation). Furthermore, tDCS showed significant generalization of improvement in sound duration relative to sham. Taken together our findings suggest that tDCS has the potential to improve AOS symptoms. This is particularly important for nfvPPA/AOS since some patients may only present with AOS symptomatology at least in initial stages [13,21].

The tDCS montage in the present study targeted the left IFG. As discussed in the Introduction, the left IFG, and in particular the left IFG opercularis, is associated with articulatory motor planning and is adjacent to the primary motor areas of the mouth and tongue $[84,85]$. Given the size of our electrodes $(2 \times 2$ inches), we cannot claim that we targeted only the left IFG or the IFG opercularis, although this area would be functionally related to AOS symptoms. Recent evidence of the principle of 'functional targeting' in the tDCS literature, concurs with the opinion that the current flows only on active cells, those related to the function that is trained [86]. Our previous study has shown that a possible mechanism for tDCS effects is through changes in functional connectivity of the stimulated area, the left IFG, in particular [19]. Although stimulation over the left IFG improved speech production, our findings do not exclude a speech improvement due to stimulation over homologue areas in the right hemisphere or other adjacent areas of the premotor cortex or the insula [87]. A subsequent functional connectivity study would need to provide evidence that this particular stimulation montage caused the present effects of segmental duration of vowels and consonants.

TDCS resulted in shorter vowels and consonants, yet the effects were greater on vowels than consonants. This is not surprising, since vowels and especially stressed vowels, are intrinsically longer than most consonants [22,57], and this is the case even for geminate consonants in languages that have geminates, such as Finnish and Estonian. Therefore, this effect may not reflect a selective effect on vowels but rather opportunities for shortening. There are several underlying causes for these intrinsic differences between vowels and consonants, such as stress, post-lexical prominence (nuclear or pronuclear pitch accents), or phonetic distribution of lengthening over the syllable onset nucleus and coda, which are language specific effects and further discussion would be beyond the scope of this paper. Sound duration is affected by both articulatory and linguistic parameters. Articulatory factors that affect sound duration may be related to articulatory planning, coordination, and timing of neural commands, execution of articulatory movements, control of the airflow from the lungs towards the oral cavity and the vocal fold vibration in the larynx [56,88-91]. Additionally, phonemic factors that affect sound duration may be related to lexical stress, accentual 
prominence, lengthening effects demarcating the boundaries of words and phrases, speech fluency, and other communicative effects, such as emphasis [92]. In other words, sound duration is better seen as an integral measure of different processes affecting speech production. The fact that sound duration is improved means that it could be the effect of a multidomain improvement either articulatory or linguistic (lung air pressure, vocal fold vibration, articulatory target approximation, etc.). The additional effects of articulatory deficits in nfvPPA/AOS, may explain why temporal properties of speech have been shown to distinguish patients with AOS from other patients with PPA $[8,20,21]$.

One remaining question is whether tDCS effects transfer to post-lexical coarticulation level phenomena and prosodic phenomena, such as phrasing, intonation, speech fluency, and speech rate that involve post-lexical processes. Word repetition provides very limited information on phrasing, partly because phrasing here would be defined as a measure between clinician-patient-clinician productions (which is partly determined by the clinician). With respect to intonation, it is difficult to study pitch accents (a nuclear pitch accent, a phrase accent, and a boundary tone) at the word level [93]. By studying only F0, it would be very difficult to explain what constitutes an amelioration of the deficit vs. normalization. Furthermore, speech fluency and speech rate require sentence level productions. Nevertheless, segmental duration should be highly correlated with these sentence-level measures, as reduced segmental duration would indicate faster sentence production. Future studies should also incorporate connected speech productions.

The main limitation of this study is the small number of participants, and therefore it can only be considered as a preliminary, proof-of-concept study. A related possible limitation is the matching of participants between the two stimulation groups. We matched the patients with respect to the language component of the FTD-CDR. The participants in the sham group seemed to have a little higher overall severity score, although the difference was not very large (4.67 out of possible 27 in the sham group and 1.5 out of 27 in the tDCS group). The overall severity of the FTD-CDR includes the language component but also provides additional scores for memory, orientation, judgement, community affairs, home and hobbies, personal care, and behavior. Although it is possible to entertain that overall severity differences in other than language sections of the FTD-CDR may impact AOS treatment and $\mathrm{tDCS}$ effects, the two stimulation groups were matched at baseline on the AOS outcome measure (sound duration). This, in conjunction with their matched language severity, suggests that the overall severity differences did not affect the outcome measures.

Similarly, patient differences in letter fluency (FAS), and syntactic comprehension (SOAP) were not reflected on sound duration at baseline (the dependent variable of this study) as both groups exhibited approximately the same mean sound duration as shown in Figure 3. If differences in performance on letter fluency or syntactic comprehension tasks influence the neuromodulatory effect of tDCS on sound duration as a primary AOS symptom, it remains an empirical question. Such a finding would rather speak against the consensus classification, i.e., against the fact that nfvPPA is a unitary variant. Rather, it should be split in two as Duffy et al., 2017 have argued: one with AOS symptoms (PPAOS) but without initial fluency or syntactic deficits and another with initial fluency and syntactic deficits and no AOS symptoms. Nevertheless, we acknowledge these differences in the statistics we run, by considering the participant as a random slope.

Another possible limitation is the inherent diffusivity in tDCS methodology, including the lack of specific current flow estimation for each of the present participants. Nevertheless, previous current modeling in Figure 1 showed that the current distribution was centered in the left IFG. The choice for the $5 \times 5 \mathrm{~cm}^{2}$ electrode patches in our tDCS montage in the present study as well as in most previous clinical studies is driven by the premise and ease of transferring this methodology to clinic, if shown to be efficacious. Although not as precise as other tDCS methodologies, such as high-definition tDCS, the inherent large spread of electrical current in the present and other clinical studies, may actually be the very reason of their efficacy as the current affects larger brain regions. Future studies comparing these methods are needed to determine their clinical efficacy. 


\section{Conclusions}

To our knowledge, despite the high prevalence of AOS in PPA, namely nfvPPA, there is no evidence as to whether tDCS may be a useful adjunct to speech therapy in nfvPPA patients with AOS symptomatology. The findings of the present proof-of-concept study, i.e., the remarkable improvement in sound duration immediately after and even up to 2 months post-treatment, shows that $\mathrm{tDCS}$ has the potential to enhance speech production in patients with nfvPPA/AOS and warrants a larger study of tDCS over the left IFG as a therapeutic approach to improve AOS symptoms in nfvPPA/AOS. Furthermore, the sustainability of the tDCS's effects provides the premise that $\mathrm{tDCS}$ combined with AOS treatment may inhibit the progression of AOS symptoms in patients with nfvPPA/AOS whose language deteriorates over time due to the nature of neurodegenerative disease. Therefore, a larger behavioral and neuroimaging study is warranted to specifically test the clinical efficacy of tDCS in AOS and the neural structures involved.

Author Contributions: Conceptualization, K.T. and C.T.; methodology, C.T.; software, C.T.; validation, C.T. and K.T.; formal analysis, C.T.; investigation, C.T.; resources, K.T.; data curation, K.T.; writing —original draft preparation, C.T.; writing—review and editing, C.T., K.W. and K.T.; visualization, C.T.; supervision, K.T. and CT; project administration, K.W.; funding acquisition, K.T. All authors have read and agreed to the published version of the manuscript.

Funding: This research was funded by Science of Learning Institute at Johns Hopkins University and by the National Institutes of Health (National Institute of Deafness and Communication Disorders), grant number NIH/NIDCD R01 DC014475.

Institutional Review Board Statement: Ethics approval for the study was provided by the Johns Hopkins Hospital Institutional Review Board (IRB NA00071337).

Informed Consent Statement: Informed consent was obtained from all subjects involved in the study.

Data Availability Statement: Data are available after request; sound recordings are not available as they can identify the speaker.

Acknowledgments: We want to thank Olivia Herman for proofreading the final manuscript and providing useful editorial comments.

Conflicts of Interest: The authors declare no conflict of interest.

\section{Appendix A}

\begin{tabular}{|c|c|c|c|}
\hline Set Lists & & Word Triplets & \\
\hline \multirow[t]{10}{*}{ SET 1} & intervene & intervention & interventional \\
\hline & progress & progression & progressive \\
\hline & reflect & reflection & reflective \\
\hline & stimulate & stimulation & stimulating \\
\hline & stable & stabilize & stabilization \\
\hline & success & successful & successfully \\
\hline & excite & excitable & excitability \\
\hline & improve & improvement & improving \\
\hline & behave & behavioral & behaviorally \\
\hline & perform & performance & performing \\
\hline \multirow[t]{10}{*}{ SET 2} & enhance & enhancement & enhancing \\
\hline & suspend & suspension & suspending \\
\hline & suppress & suppression & suppressive \\
\hline & construct & construction & constructive \\
\hline & accurate & accuracy & inaccurate \\
\hline & therapy & therapeutic & therapeutically \\
\hline & provide & provision & provisional \\
\hline & hypothesis & hypothesize & hypothetical \\
\hline & define & definition & definitive \\
\hline & determine & determination & determining \\
\hline
\end{tabular}




\begin{tabular}{cccc}
\hline Set Lists & Word Triplets & \\
\hline SET 3 & inform & information & informative \\
& suppose & supposition & supposedly \\
& restrict & restriction & restrictive \\
& concentrate & concentration & concentrated \\
inhibit & inhibition & inhibiting \\
& investigate & investigation & investigator \\
& combine & combination & combinatory \\
& cognition & cognitive & cognitively \\
& method & methodology & methodological \\
& courage & courageous & encouraging \\
\hline
\end{tabular}

\section{Appendix B}

In addition to the quantified measurements, we observed several co-articulatory and phonemic processes that were characteristic of the productions in individuals with nfvPPA/AOS, such as several phenomena that were observed in re-occurring speech of these individuals. Specifically, voiceless consonants were often produced as voiced before

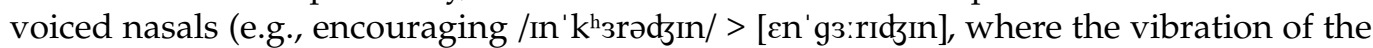
vocal folds during the production of the nasal/n/does not cease before the production of the adjacent voiceless consonant $/ \mathrm{k} /$ ). Voiced consonants were often produced as devoiced (definitive /dI' finitıv/ > [ $t^{\mathrm{t}^{\mathrm{h}} \mathrm{IVInI}} \mathrm{t}^{\mathrm{h}} \mathrm{IV}$ ]; aspiration results from the phonemic rule in English that aspirates onset stop consonants [94]. Overshooting or undershooting of articulatory

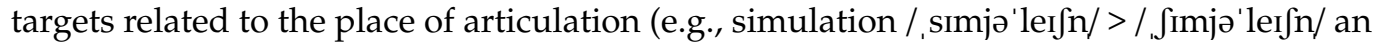
alveolar fricative sound becomes postalveolar fricative when it approaches an alveopalatal consonant). Spirantization phenomena were especially common at word codas $(\mathrm{d}>\circlearrowright$ ):

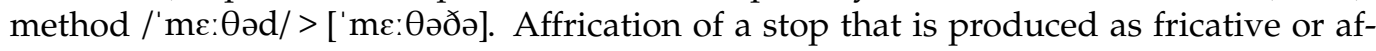

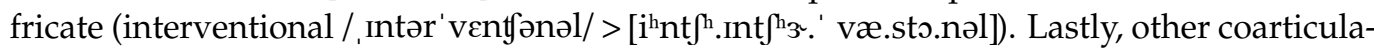
tory phenomena were also observed, such as cluster simplification: (the/st/): stable/'sterbl/

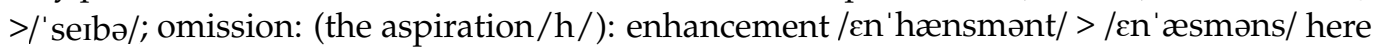
the articulatory command for its production fails to activate). Compensatory measures to produce lexical stress: i. longer syllable duration; ii. splitting the stressed syllable from the preceding part: excitability /Ik, sarta'biliti/ > [Ik, sartə. 'biliti]. Slow speech production and effortful speech. To explain the complex interactions between brain areas and impairment in patients with nfvPPA/AOS, cognitive models were developed for apraxia of speech often based on language models, such as those proposed by Levelt [95] and aim to describe the processes involved in apraxia modeling the invariant and variant aspects of speech production $[96,97]$.

\section{References}

1. Ogar, J.; Willock, S.; Baldo, J.; Wilkins, D.; Ludy, C.; Dronkers, N. Clinical and anatomical correlates of apraxia of speech. Brain Lang. 2006, 97, 343-350. [CrossRef] [PubMed]

2. Jordan, L.C.; Hillis, A.E. Disorders of speech and language: Aphasia, apraxia and dysarthria. Curr Opin Neurol 2006, 19, 580-585. [CrossRef]

3. Graff-Radford, J.; Jones, D.T.; Strand, E.A.; Rabinstein, A.A.; Duffy, J.R.; Josephs, K.A. The neuroanatomy of pure apraxia of speech in stroke. Brain Lang. 2014, 129, 43-46. [CrossRef]

4. Moser, D.; Basilakos, A.; Fillmore, P.; Fridriksson, J. Brain damage associated with apraxia of speech: Evidence from case studies. Neurocase 2016, 22, 346-356. [CrossRef]

5. Rosenbek, J.C.; Lemme, M.L.; Ahern, M.B.; Harris, E.H.; Wertz, R.T. A treatment for apraxia of speech in adults. J. Speech Hear. Disord. 1973, 38, 462-472. [CrossRef] [PubMed]

6. Ogar, J.; Slama, H.; Dronkers, N.; Amici, S.; Gorno-Tempini, M.L. Apraxia of speech: An overview. Neurocase 2005, 11, 427-432. [CrossRef] [PubMed]

7. Josephs, K.A.; Duffy, J.R. Apraxia of speech and nonfluent aphasia: A new clinical marker for corticobasal degeneration and progressive supranuclear palsy. Curr. Opin. Neurol. 2008, 21, 688-692. [CrossRef] [PubMed]

8. Laganaro, M.; Croisier, M.; Bagou, O.; Assal, F. Progressive apraxia of speech as a window into the study of speech planning processes. Cortex 2012, 48, 963-971. [CrossRef]

9. Trupe, L.A.; Varma, D.D.; Gomez, Y.; Race, D.; Leigh, R.; Hillis, A.E.; Gottesman, R.F. Chronic apraxia of speech and Broca's area. Stroke 2013, 44, 740-744. [CrossRef] 
10. Mesulam, M.M. Primary progressive aphasia-A language-based dementia. N. Engl. J. Med. 2003, 349, 1535-1542. [CrossRef]

11. Grossman, M. Progressive aphasic syndromes: Clinical and theoretical advances. Curr. Opin. Neurol. 2002, 15, 409-413. [CrossRef] [PubMed]

12. Grossman, M. Primary progressive aphasia: Clinicopathological correlations. Nat. Rev. Neurol. 2010, 6, 88-97. [CrossRef]

13. Gorno-Tempini, M.L.; Hillis, A.E.; Weintraub, S.; Kertesz, A.; Mendez, M.; Cappa, S.F.; Ogar, J.M.; Rohrer, J.D.; Black, S.; Boeve, B.F.; et al. Classification of primary progressive aphasia and its variants. Neurology 2011, 76, 1006-1014. [CrossRef] [PubMed]

14. Thompson, C.K.; Cho, S.; Hsu, C.J.; Wieneke, C.; Rademaker, A.; Weitner, B.B.; Mesulam, M.M.; Weintraub, S. Dissociations Between Fluency And Agrammatism In Primary Progressive Aphasia. Aphasiology 2012, 26, 20-43. [CrossRef] [PubMed]

15. Duffy, J.R. Apraxia of speech in degenerative neurologic disease. Aphasiology 2006, 20, 511-527. [CrossRef]

16. Duffy, J.R.; Strand, E.A.; Clark, H.; Machulda, M.; Whitwell, J.L.; Josephs, K.A. Primary progressive apraxia of speech: Clinical features and acoustic and neurologic correlates. Am. J. Speech Lang. Pathol. 2015, 24, 88-100. [CrossRef]

17. Josephs, K.A.; Duffy, J.R.; Strand, E.A.; Whitwell, J.L.; Layton, K.F.; Parisi, J.E.; Hauser, M.F.; Witte, R.J.; Boeve, B.F.; Knopman, D.S.; et al. Clinicopathological and imaging correlates of progressive aphasia and apraxia of speech. Brain 2006, 129, 1385-1398. [CrossRef]

18. Josephs, K.A.; Whitwell, J.L.; Duffy, J.R.; Vanvoorst, W.A.; Strand, E.A.; Hu, W.T.; Boeve, B.F.; Graff-Radford, N.R.; Parisi, J.E.; Knopman, D.S.; et al. Progressive aphasia secondary to Alzheimer disease vs FTLD pathology. Neurology 2008, 70, 25-34. [CrossRef]

19. Marangolo, P.; Marinelli, C.V.; Bonifazi, S.; Fiori, V.; Ceravolo, M.G.; Provinciali, L.; Tomaiuolo, F. Electrical stimulation over the left inferior frontal gyrus (IFG) determines long-term effects in the recovery of speech apraxia in three chronic aphasics. Behav. Brain Res. 2011, 225, 498-504. [CrossRef]

20. Utianski, R.L.; Duffy, J.R.; Clark, H.M.; Strand, E.A.; Botha, H.; Schwarz, C.G.; Machulda, M.M.; Senjem, M.L.; Spychalla, A.J.; Jack, C.R., Jr.; et al. Prosodic and phonetic subtypes of primary progressive apraxia of speech. Brain Lan.g 2018, 184, 54-65. [CrossRef]

21. Duffy, J.R.; Hanley, H.; Utianski, R.; Clark, H.; Strand, E.; Josephs, K.A.; Whitwell, J.L. Temporal acoustic measures distinguish primary progressive apraxia of speech from primary progressive aphasia. Brain Lang. 2017, 168, 84-94. [CrossRef]

22. Themistocleous, C.; Ficek, B.; Webster, K.; den Ouden, D.-B.; Hillis, A.E.; Tsapkini, K. Automatic Subtyping of Individuals with Primary Progressive Aphasia. J. Alzheimer's Dis. 2021, 79, 1185-1194. [CrossRef]

23. Ballard, K.J.; Azizi, L.; Duffy, J.R.; McNeil, M.R.; Halaki, M.; O’Dwyer, N.; Layfield, C.; Scholl, D.I.; Vogel, A.P.; Robin, D.A. A predictive model for diagnosing stroke-related apraxia of speech. Neuropsychologia 2016, 81, 129-139. [CrossRef] [PubMed]

24. Basilakos, A. Towards Improving the Evaluation of Speech Production Deficits in Chronic Stroke; University of South Carolina: Los Angeles, CA, USA, 2016.

25. Collins, M.; Rosenbek, J.C.; Wertz, R.T. Spectrographic analysis of vowel and word duration in apraxia of speech. J. Speech Hear. Res. 1983, 26, 224-230. [CrossRef]

26. Kent, R.D.; Rosenbek, J.C. Acoustic patterns of apraxia of speech. J. Speech Hear. Res. 1983, 26, 231-249. [CrossRef]

27. Hardcastle, W.J. Electropalatographic study of articulation disorders in verbal dyspraxia. In Phonetic Approaches to Speech Production in Aphasia and Related Disorders; Ryalls, J.H., Ed.; College-Hill Press: Boston, MA, USA, 1987; pp. 113-136.

28. Itoh, M. Articulatory movements in apraxia of speech. In Apraxia of Speech: Physiology, Acoustics, Linguistics, Management; Ryalls, J.H., Ed.; College Hill: Boston, MA, USA, 1984; pp. 135-165.

29. Itoh, M.; Sasanuma, S.; Tatsumi, I.F.; Murakami, S.; Fukusako, Y.; Suzuki, T. Voice onset time characteristics in apraxia of speech. Brain Lang. 1982, 17, 193-210. [CrossRef]

30. Cunningham, K.T.; Haley, K.L.; Jacks, A. Speech sound distortions in aphasia and apraxia of speech: Reliability and diagnostic significance. Aphasiology 2016, 30, 396-413. [CrossRef]

31. Varley, R.A.; Whiteside, S.P. Voicing in severe apraxia of speech: Perceptual and acoustic analysis of a single case. J. Neurolinguistics 1998, 11, 259-273. [CrossRef]

32. Mauszycki, S.C.; Dromey, C.; Wambaugh, J.L. Variability in apraxia of speech: A perceptual, acoustic, and kinematic analysis of stop consonants. J. Med. Speech-Lang. Pathol. 2007, 15, 223-242.

33. Haley, K.L. Temporal and spectral properties of voiceless fricatives in aphasia and apraxia of speech. Aphasiology 2002, 16, 595-607. [CrossRef]

34. Haley, K.L.; Jacks, A. Word-level prosodic measures and the differential diagnosis of apraxia of speech. Clin. Linguist. Phon. 2019, 33, 479-495. [CrossRef]

35. Hillis, A.E.; Work, M.; Barker, P.B.; Jacobs, M.A.; Breese, E.L.; Maurer, K. Re-examining the brain regions crucial for orchestrating speech articulation. Brain 2004, 127, 1479-1487. [CrossRef] [PubMed]

36. Ogar, J.M.; Dronkers, N.F.; Brambati, S.M.; Miller, B.L.; Gorno-Tempini, M.L. Progressive nonfluent aphasia and its characteristic motor speech deficits. Alzheimer Dis. Assoc. Disord. 2007, 21, S23-S30. [CrossRef] [PubMed]

37. Alexander, M.P.; Benson, D.F.; Stuss, D.T. Frontal lobes and language. Brain Lang. 1989, 37, 656-691. [CrossRef]

38. Dronkers, N.F. A new brain region for coordinating speech articulation. Nature 1996, 384, 159-161. [CrossRef] [PubMed]

39. Saur, D.; Kreher, B.W.; Schnell, S.; Kummerer, D.; Kellmeyer, P.; Vry, M.S.; Weiller, C. Ventral and dorsal pathways for language. Proc. Natl. Acad. Sci.USA 2008, 105, 18035. [CrossRef]

40. Hickok, G.; Poeppel, D. The cortical organization of speech processing. Nat. Rev. Neurosci. 2007, 8, 393-402. [CrossRef] [PubMed] 
41. Peach, R.K.; Tonkovich, J.D. Phonemic characteristics of apraxia of speech resulting from subcortical hemorrhage. J. Commun. Disord. 2004, 37, 77-90. [CrossRef]

42. Henry, M.L.; Meese, M.V.; Truong, S.; Babiak, M.C.; Miller, B.L.; Gorno-Tempini, M.L. Treatment for apraxia of speech in nonfluent variant primary progressive aphasia. Behav. Neurol. 2013, 26, 77-88. [CrossRef]

43. Harris, A.D.; Wang, Z.; Ficek, B.; Webster, K.; Edden, R.A.E.; Tsapkini, K. Reductions in GABA following a tDCS-language intervention for primary progressive aphasia. Neurobiol. Aging 2019, 79, 75-82. [CrossRef]

44. Antonenko, D.; Schubert, F.; Bohm, F.; Ittermann, B.; Aydin, S.; Hayek, D.; Grittner, U.; Fl $\sqrt{ }$ del, A. tDCS-Induced Modulation of GABA Levels and Resting-State Functional Connectivity in Older Adults. J. Neurosci. Off. J. Soc. Neurosci. 2017, 37, 4065-4073. [CrossRef]

45. Stagg, C.J.; Nitsche, M.A. Physiological basis of transcranial direct current stimulation. Neurosci. Rev. J. Bringing Neurobiol. Neurol. Psychiatry 2011, 17, 37-53. [CrossRef]

46. Ficek, B.N.; Wang, Z.; Zhao, Y.; Webster, K.T.; Desmond, J.E.; Hillis, A.E.; Frangakis, C.; Faria, A.V.; Caffo, B.; Tsapkini, K. The effect of tDCS on functional connectivity in primary progressive aphasia. Neuroimage Clin. 2018. [CrossRef]

47. Chesters, J.; Watkins, K.E.; Möttönen, R. Investigating the feasibility of using transcranial direct current stimulation to enhance fluency in people who stutter. Brain Lang. 2017, 164, 68-76. [CrossRef] [PubMed]

48. Chesters, J.; Mottonen, R.; Watkins, K.E. Transcranial direct current stimulation over left inferior frontal cortex improves speech fluency in adults who stutter. Brain 2018, 141, 1161-1171. [CrossRef]

49. Buchwald, A.; Calhoun, H.; Rimikis, S.; Lowe, M.S.; Wellner, R.; Edwards, D.J. Using tDCS to facilitate motor learning in speech production: The role of timing. Cortex 2019, 111, 274-285. [CrossRef]

50. Tsapkini, K.; Frangakis, C.; Davis, C.; Gomez, Y.; Chakravarty, T.; Hillis, A. Spelling rehabilitation using transcranial direct current (tDCS) in primary progressive aphasia (PPA). Front. Psychol. 2014, 5, 1.

51. Tsapkini, K.; Frangakis, C.; Gomez, Y.; Davis, C.; Hillis, A.E. Augmentation of spelling therapy with transcranial direct current stimulation in primary progressive aphasia: Preliminary results and challenges. Aphasiology 2014, 28, 1112-1130. [CrossRef]

52. de Aguiar, V.; Zhao, Y.; Ficek, B.N.; Webster, K.; Rofes, A.; Wendt, H.; Frangakis, C.; Caffo, B.; Hillis, A.E.; Rapp, B.; et al. Cognitive and language performance predicts effects of spelling intervention and tDCS in Primary Progressive Aphasia. Cortex 2020, 124, 66-84. [CrossRef]

53. Tsapkini, K.; Webster, K.T.; Ficek, B.N.; Desmond, J.E.; Onyike, C.U.; Rapp, B.; Frangakis, C.E.; Hillis, A.E. Electrical brain stimulation in different variants of primary progressive aphasia: A randomized clinical trial. Alzheimers Dement. 2018, 4, 461-472. [CrossRef]

54. Roncero, C.; Kniefel, H.; Service, E.; Thiel, A.; Probst, S.; Chertkow, H. Inferior parietal transcranial direct current stimulation with training improves cognition in anomic Alzheimer's disease and frontotemporal dementia. Alzheimers Dement. 2017, 3, 247-253. [CrossRef] [PubMed]

55. McConathey, E.M.; White, N.C.; Gervits, F.; Ash, S.; Coslett, H.B.; Grossman, M.; Hamilton, R.H. Baseline Performance Predicts tDCS-Mediated Improvements in Language Symptoms in Primary Progressive Aphasia. Front. Hum. Neurosci. 2017, 11, 347. [CrossRef]

56. Byrd, D.; Saltzman, E. The elastic phrase: Modeling the dynamics of boundary-adjacent lengthening. J. Phon. 2003, 31, 149-180. [CrossRef]

57. Themistocleous, C. Edge-Tone Effects and Prosodic Domain Effects on Final Lengthening. Linguist. Var. 2014, 14, 129-160. [CrossRef]

58. Howard, D.; Patterson, K. The Pyramid and Palm Trees Test: A Test of Semantic Access from Words and Pictures; Thames Valley Test Company: Bury St. Edmunds, UK, 1992.

59. Kaplan, E.; Goodglass, H.; Weintraub, S. Boston Naming Test; Pro-Ed: Austin, TX, USA, 2001.

60. Love, T.; Oster, E. On the categorization of aphasic typologies: The SOAP (a test of syntactic complexity). J. Psycholinguist Res. 2002, 31, 503-529. [CrossRef]

61. Spreen, O.; Benton, A.L. Neurosensory Center Comprehensive Examination for Aphasia: Manual of Directions, Revised Edition; Department of Psychology, University of Victoria: Vicotria, BC, Canada, 1977.

62. Knopman, D.S.; Kramer, J.H.; Boeve, B.F.; Caselli, R.J.; Graff-Radford, N.R.; Mendez, M.F.; Miller, B.L.; Mercaldo, N. Development of methodology for conducting clinical trials in frontotemporal lobar degeneration. Brain 2008, 131, 2957-2968. [CrossRef]

63. Dabul, B. ABA-2: Apraxia Battery for Adults: Examiner's Manual; Pro-Ed: Austin, TX, USA, 2000.

64. Unal, G.; Ficek, B.; Webster, K.; Shahabuddin, S.; Truong, D.; Hampstead, B.; Bikson, M.; Tsapkini, K. Impact of brain atrophy on tDCS and HD-tDCS current flow: A modeling study in three variants of primary progressive aphasia. Neurol. Sci. Off. J. Ital. Neurol. Soc. Ital. Soc. Clin. Neurophysiol. 2020, 41, 1781-1789. [CrossRef]

65. de Aguiar, V.; Zhao, Y.; Faria, A.; Ficek, B.; Webster, K.T.; Wendt, H.; Wang, Z.; Hillis, A.E.; Onyike, C.U.; Frangakis, C.; et al. Brain volumes as predictors of tDCS effects in primary progressive aphasia. Brain Lang. 2020, 200, 104707. [CrossRef]

66. Senn, S. Cross-Over Trials in Clinical Research, 2nd ed.; John Wiley \& Sons, Ltd.: New York, NY, USA, 2002.

67. Purcell, J.J.; Turkeltaub, P.E.; Eden, G.F.; Rapp, B. Examining the central and peripheral processes of written word production through meta-analysis. Front. Psychol. 2011, 2, 239. [CrossRef]

68. Price, C.J. A review and synthesis of the first 20years of PET and fMRI studies of heard speech, spoken language and reading. NeuroImage 2012, 62, 816-847. [CrossRef] 
69. Homan, R.W.; Herman, J.; Purdy, P. Cerebral location of international 10-20 system electrode placement. Electroencephalogr. Clin. Neurophysiol. 1987, 66, 376-382. [CrossRef]

70. Gandiga, P.C.; Hummel, F.C.; Cohen, L.G. Transcranial DC stimulation (tDCS): A tool for double-blind sham-controlled clinical studies in brain stimulation. Clin. Neurophysiol 2006, 117, 845-850. [CrossRef]

71. Peterson, G.E.; Lehiste, I. Duration of Syllable Nuclei in English. J. Acoust. Soc. Am. 1960, 32, 693-703. [CrossRef]

72. Themistocleous, C. The Nature of Phonetic Gradience across a Dialect Continuum: Evidence from Modern Greek Vowels. Phonetica 2017, 74, 157-172. [CrossRef] [PubMed]

73. Themistocleous, C. Dialect classification using vowel acoustic parameters. Speech Commun. 2017, 92, 13-22. [CrossRef]

74. Themistocleous, C.; Savva, A.; Aristodemou, A. Effects of stress on fricatives: Evidence from Standard Modern Greek. In Proceedings of the Interspeech 2016, San Francisco, CA, USA, 8-12 September 2016; pp. 1-4.

75. Themistocleous, C. Dialect Classification From a Single Sonorant Sound Using Deep Neural Networks. Front. Commun. 2019, 4, 1-12. [CrossRef]

76. Themistocleous, C. The bursts of stops can convey dialectal information. J. Acoust. Soc. Am. 2016, 140, EL334-EL339. [CrossRef] [PubMed]

77. Boersma, P.; Weenink, D. Praat: Doing Phonetics by Computer (Version 6.0.37); University of Amsterdam: Amsterdam, The Netherlands, 2018.

78. Baayen, R.H. Analyzing Linguistic Data: A Practical Introduction to Statistics Using R; Cambridge University Press: Cambridge, UK, 2008.

79. Schielzeth, H.; Dingemanse, N.J.; Nakagawa, S.; Westneat, D.F.; Allegue, H.; Teplitsky, C.; Réale, D.; Dochtermann, N.A.; Garamszegi, L.Z.; Araya-Ajoy, Y.G. Robustness of linear mixed-effects models to violations of distributional assumptions. Methods Ecol. Evol. 2020, 11, 1141-1152. [CrossRef]

80. R Core Team. R: A Language and Environment for Statistical Computing; R Foundation for Statistical Computing: Vienna, Austria, 2020.

81. Bates, D.; Mächler, M.; Bolker, B.; Walker, S. Fitting Linear Mixed-Effects Models Using lme4. J. Stat. Softw. 2015, 67, 1-48. [CrossRef]

82. Kuznetsova, A.; Bruun Brockhoff, P.; Haubo Bojesen Christensen, R. lmerTest: Tests in Linear Mixed Effects Models; R Foundation for Statistical Computing: Vienna, Austria, 2016.

83. Russell, L. emmeans: Estimated Marginal Means, aka Least-Squares Means; R Foundation for Statistical Computing: Vienna, Austria, 2020.

84. Margulies, D.S.; Petrides, M. Distinct parietal and temporal connectivity profiles of ventrolateral frontal areas involved in language production. J. Neurosci 2013, 33, 16846-16852. [CrossRef] [PubMed]

85. Wang, J.; Wu, D.; Cheng, Y.; Song, W.; Yuan, Y.; Zhang, X.; Zhang, D.; Zhang, T.; Wang, Z.; Tang, J.; et al. Effects of Transcranial Direct Current Stimulation on Apraxia of Speech and Cortical Activation in Patients With Stroke: A Randomized Sham-Controlled Study. Am. J. Speech-Lang. Pathol. 2019, 28, 1625-1637. [CrossRef]

86. Bikson, M.; Grossman, P.; Thomas, C.; Zannou, A.L.; Jiang, J.; Adnan, T.; Mourdoukoutas, A.P.; Kronberg, G.; Truong, D.; Boggio, P.; et al. Safety of Transcranial Direct Current Stimulation: Evidence Based Update 2016. Brain Stimul. 2016, 9, 641-661. [CrossRef]

87. Marangolo, P.; Fiori, V.; Cipollari, S.; Campana, S.; Razzano, C.; Paola, M.D.; Koch, G.; Caltagirone, C. Bihemispheric stimulation over left and right inferior frontal region enhances recovery from apraxia of speech in chronic aphasia. Eur. J. Neurosci. 2013, 38, 3370-3377. [CrossRef]

88. Lehiste, I. Suprasegmentals; MIT Press: Cambridge, MA, USA, 1970.

89. Ohala, J. The application of phonological universals in speech pathology. Speech Lang. 1980, 3, 75-97.

90. Stevens, K.N. Acoustic Phonetics; MIT Press: Cambridge, MA, USA, 1998.

91. Fant, G. Acoustic Theory of Speech Production. Slav. East. Eur. J. 1960, 5, 285. [CrossRef]

92. Themistocleous, C. Seeking an Anchorage. Stability and Variability in Tonal Alignment of Rising Prenuclear Pitch Accents in Cypriot Greek. Lang. Speech 2016, 59, 433-461. [CrossRef]

93. Pierrehumbert, J. Phonology and Phonetics of English Intonation; Massachusetts Institute of Technology: Boston, MA, USA, 1980.

94. Cruttenden, A. Gimson's Pronunciation of English, 7th ed.; Hodder Education: London, UK, 2008.

95. Levelt, W.J.M. Speaking: From Intention to Articulation; MIT Press: Cambridge, MA, USA, 1993.

96. Kelso, J.A.; Tuller, B. Toward a theory of apractic syndromes. Brain Lang. 1981, 12, 224-245. [CrossRef]

97. Whiteside, S.P.; Varley, R.A. A reconceptualisation of apraxia of speech: A synthesis of evidence. Cortex 1998, 34, 221-231. [CrossRef] 